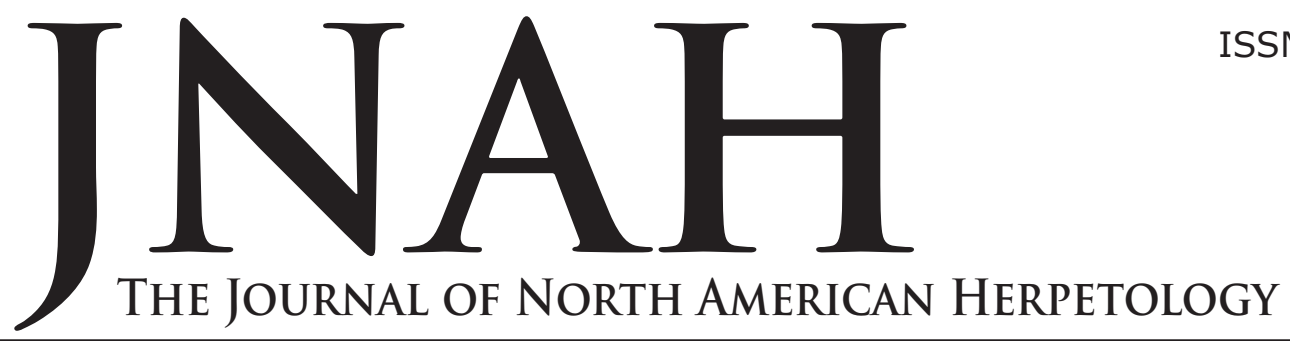

ISSN 2333-0694

Volume 2021, Number 1

June 2021

journals.ku.edu/jnah

\title{
AGGRESSIVE BEHAVIORS AND THEIR EFFECT ON RESOURCE USE BY FEMALE SCINCELLA LATERALIS
}

\author{
LAURA MYERS ${ }^{1}$ AND MARK PAULISSEN² \\ Department of Curriculum and Instruction, Northeastern State University, \\ Tahlequah, Oklahoma 74464 \\ and Department of Natural Sciences, Northeastern State University, Tahlequah, Oklahoma 74464 \\ ${ }^{1}$ Present address: Grand View Middle School, 15481 North Jarvis Rd, Tahlequah, OK 74464 - Imyers@ \\ grandviewchargers.org \\ ${ }^{2}$ Corresponding author: paulisse@nsuok.edu
}

\begin{abstract}
Studies of aggression and space use are essential to understanding resource use by reptiles, particularly lizards. Research in this area, however, exhibits bias in that the seminal work has been done on (1) species that are highly visible in their habitats (e.g. Iguanians); and (2) males. Studies of secretive species such as skinks and of females are less common. Here, we present results of a lab study of dyadic encounters of adult females of a common North American skink: Scincella lateralis (Little Brown Skink), and compare them to results obtained from an earlier study of adult males of the same species. Female $S$. lateralis never interacted unless they were within one body length of each other. The most common behavior exhibited was avoidance of one lizard (the subordinate) away from the other lizard (the dominant). As a result, the two lizards spent more time apart than close together and rarely shared the retreat. The larger of the two females was dominant in 9 of 10 trials. Compared to adult males, adult females showed far fewer aggressive behaviors such as lunging or chasing, and never bit each other. Unlike males, however, subordinate female S. lateralis exhibited tail twitching significantly more often than did dominants, suggesting this behavior may be a social signal for females, though the data suggest there may be other possible functions. Despite differences in the frequency of behaviors exhibited, patterns of space use and retreat use were the same in females as they were in males.
\end{abstract}

Key Words: Scincella, Female, Behavior, Aggression

\section{INTRODUCTION}

The study of lizard behavior has benefitted greatly from observation and analysis of the behavior of North American species. In particular, studies of North American species within the Iguania clade (sensu Sites et al. 2011) form the foundation of herpetology's understanding of communication and territoriality in lizards (reviewed in Carpenter and Ferguson 1977; Stamps 1977). In general, North American iguanians communicate with each other via visual displays including "head bobs" or "push-ups" in which the lizard raises then lowers its head and/or front end of its body in a stereotypical pattern (Carpenter 1978). Such visual displays are employed for communication related to territorial defense or reproduction in many lizard species, including members of the North American genera Sceloporus (Sheldahl and Martins 2000; Haenel et al. 2003), Crotaphytus (Baird et al. 2001; Baird 2013; York and Baird 2017), and Uta (Fox et al. 1981). Results of such studies have made it possible to probe the relationship between phylogeny and territoriality in lizards (Stamps 1977; Martins 1994; Vitt and Caldwell 2014).
Though study of Iguanian lizards has provided the basic framework for analysis of lizard behavior, the resulting knowledge is limited by two factors. The first is a taxonomic bias: the seminal studies that have been done on Iguanian species leaves other families of lizards, including one of the world's largest and most diverse families, the Scincidae, dramatically under-represented in studies of lizard behavior. Skink behavior is often more difficult to study than the behavior of Iguanians because they are typically more secretive and do not rely as extensively on visual displays (Stamps 1977). Among North American skink species, Plestiodon laticeps, the Broad-headed Skink, is probably the best studied. It has been shown to exhibit pronounced intrasexual aggression such as fighting and biting during the breeding season (Cooper and Vitt 1987; 1997). These studies focused on the behavior of adult males; the behavior of adult females was not specifically addressed. This discrepancy highlights the second factor limiting understanding of lizard behavior: a gender bias. The majority of studies of lizard behavior have focused on adult males; the behavior of adult females is typically not addressed separately or is 
studied only when females are in the presence of adult males (Perrill 1980). However, recent studies have provided evidence that adult female lizards, including some skink species, exhibit aggressive behaviors toward other adult females. For example, Sinn et al. (2008) found that post-partum Egernia whitii, White's skink females, a social species which demonstrates maternal care of offspring, will display an open mouth or back arch display and bite models of female lizards. In the non-social species, Chalcides viridanus, the West Canary skink, the aggressive display of "snout to body" in which two lizards line up antiparallel to each other and tongue flick each other, was performed more frequently in staged dyadic encounters between females than in staged dyadic encounters between males (Sanchez-Hernandez and Molina-Borja 2019).

A common North American skink that has been the subject of behavioral studies recently is Scincella lateralis, the Little Brown Skink. Early anecdotal accounts noted S. lateralis caged together will bite each other's heads (Lewis 1951; Brooks 1967). Later, a lab study by Akin (1998) found adult male $S$. lateralis are aggressive toward each other and to adult females, but that overt aggression between females was infrequent. Recently we conducted a lab study on the behavior of adult male $S$. lateralis and found that adult males are aggressive toward each other; for example, they frequently lunged at or chased rivals, bit rivals, and occasionally engaged in vicious fights in which the jaws were locked onto the head of the rival. This aggression caused adult male S. lateralis to avoid each other, and they almost never shared a retreat (Myers and Paulissen 2017). We also found that males with larger mass tended to be dominant over lighter ones. The purpose of the current study is to describe and analyze the behaviors of adult female $S$. lateralis using the same methods we used to study the behavior of males in Myers and Paulissen (2017). The goals of this study are: (1) to describe aggressive behaviors adult female $S$. lateralis display toward each other; (2) to ascertain if such aggressive behaviors influence space use in a laboratory observation chamber or sharing of a retreat; and (3) to compare the results of this study with those of our earlier study on male $S$. lateralis to draw conclusions on gender differences in behavior.

\section{MATERIALS AND METHODS}

Study Animals and Captive Maintenance - Twenty non-gravid, adult female Scincella lateralis with intact tails were captured by hand from oak-hickory forests in Cherokee County, Oklahoma. All lizards were caught and observed in May or June 2012, 2013, or 2018, save for one pair caught and observed in July 2012. This period represents the middle of the breeding season for $S$. lateralis in Oklahoma (M. A. Paulissen, pers observ.). Other than the 2018 trials, the trials on adult females were completed during the same period as the trials on adult males reported in Myers and Paulissen (2017). Each lizard was measured ( $\mathrm{SVL}=$ snout-vent length in $\mathrm{mm}$ ) with a plastic ruler and mass was measured to the nearest $0.1 \mathrm{~g}$ using a laboratory triple-beam balance. As the minimum SVL for mature adults is $35 \mathrm{~mm}$ (Brooks 1967), only female lizards with SVL > $36 \mathrm{~mm}$ were used in this study. Each lizard was housed separately in a $30.5 \times 14.0$ $X 7.6 \mathrm{~cm}$ high clear plastic box provided with a double layer of paper towel lining the floor and a cardboard retreat consisting of a one-quarter arc of a toilet paper roll tube. Lizards could use the retreat or burrow under the paper towels to hide when they were not active. A small circular food dish was filled with 8-10 small mealworms daily; water was always available in a small water dish. Heat and light were provided by a 60 Watt standard light bulb placed $1 \mathrm{~cm}$ from the side of the plastic box and run off a timer set a $12 \mathrm{hr}: 12 \mathrm{hr}$ light:dark photoperiod cycle. Each lizard was tested within one week of capture, was tested only once, and was released near its point of capture within $24 \mathrm{~h}$ of the conclusion of its trial. We have kept small skinks in captivity using this protocol before; lizards always eat regularly and remain healthy under these conditions.

Experimental Design - The methods and materials used were identical to those used in our study of male S. lateralis reported in Myers and Paulissen (2017). A 10 -gallon glass aquarium ( $50.2 \times 26.4 \times 30.5 \mathrm{~cm}$ high) was used as an observation chamber. The back and two sides of the chamber were covered with green poster board; the front was left uncovered to allow recording of lizard behaviors. The floor of the chamber was covered by a $2 \mathrm{~cm}$ thick layer of sand and garden soil moistened slightly to approximate natural soil conditions. A pair of $60 \mathrm{~W}$ heat lamps were suspended $20 \mathrm{~cm}$ above the floor of the chamber; they were run off a timer set to the same photoperiod cycle as the individual lizard cages. The substrate of the observation chamber was moistened, turned over and mixed thoroughly, and allowed to stand unoccupied for at least 24 hours after the conclusion of one behavioral trial before a pair of skinks was placed in to begin the next trial. This was to minimize the effect that residual odors left by skinks from the previous trial might have on the behavior of skinks next trial.

A behavioral trial consisted of two phases: the acclimation phase and the experimental phase. For the acclimation phase, the observation chamber was divided into two equal sides by an opaque partition that $S$. lateralis were not capable of climbing over or digging under. Each side received heat and light from one of the $60 \mathrm{~W}$ heat lamps and was provided with a food dish containing mealworms, a water dish, and a cardboard retreat similar to the type in the individual lizard cages. A single female skink was placed in each of the two sides of the divided observation chamber. The mean \pm SE lizard SVL was $47.4 \pm 1.03 \mathrm{~mm}$; the two lizards differed in SVL by $1-13 \mathrm{~mm}$ (mean $\pm \mathrm{SE}=4.8+1.37 \mathrm{~mm}$ ) in 9 of the 10 trials. In the tenth trial, the SVL of the two female skinks was the same $(51 \mathrm{~mm})$, but they differed in mass by $0.6 \mathrm{~g}$. It was therefore possible to distinguish a "large" lizard and a "small" lizard in all 10 trials. The lizards were left undisturbed for 48 hours save for brief interruptions to resupply food or water. During this acclimation phase, each lizard was free to move around its side of the divided chamber, and to eat, drink or use the retreat as it chose. However, the two lizards were not able to interact with or see each other. This acclimation phase allowed each lizard to become familiar with its "home" side of the observation chamber and insured that odors from that lizard thoroughly permeated the substrate on the lizard's home side.

After the 48 hour acclimation phase, the experimental phase began. The partition, all food dishes, water dishes, and retreats were removed and a new, clean cardboard retreat, large enough for both lizards to fit under, was placed in the center of the now undivided observation chamber. Both lizards were free to move anywhere within their home side or within the opposite side of the observation chamber, to crawl under the retreat, or to inter- 
TABLE 1. Mean \pm SE number of times dominant and subordinate female Scincella lateralis performed various behaviors during 60-minute observation periods in the observation chamber. The P-value of paired t-tests comparing the dominant to the subordinate females is shown, and "*" indicates statistical significance $(P<0.05) ; N=10$ trials.

\begin{tabular}{cccc}
\hline & Dominant & Subordinate & $\begin{array}{c}\text { P-value of } \\
\text { t-test }\end{array}$ \\
\hline Lunge & $0.1 \pm 0.10$ & 0.0 & 0.343 \\
Chase & $1.0 \pm 0.56$ & $0.1 \pm 0.56$ & 0.095 \\
Avoid & $1.1 \pm 0.67$ & $12.4 \pm 2.00$ & $0.001^{*}$ \\
Tail Twitch & $0.3 \pm 0.21$ & $1.1 \pm 0.38$ & $0.037 *$ \\
\hline
\end{tabular}

act with each other. Lizard behaviors were continuously recorded for the next 60 minutes using a SONY REV280 analog (tape) recorder placed in front of the observation chamber (no people were present in the room at this time). After the 60 min trial was completed, both lizards were placed back in their home cages until they were released. All trials were run between 1100 and 1500 .

Data Collection and Analysis - Tapes were played back to quantify lizard behaviors and movements that occurred during the $60 \mathrm{~min}$ experimental phase trials. Shortly after a trial began, one or both lizards began to move about the observation chamber. As this happened, the two lizards frequently came to within one body length of each other (about $45 \mathrm{~mm}$ ); each such occurrence was scored as an encounter. The behaviors of both lizards were noted for each encounter following the description of behaviors presented in Table 1 of Myers and Paulissen (2017). The behaviors observed included: (1) no reaction - neither lizard showed any obvious reaction to the other; (2) lunge - one lizard runs rapidly 40-50 mm toward the other lizard (which typically responded by fleeing); (3) chase - similar to lunge except one lizard chases the other for a much greater distance $(10 \mathrm{~cm}$ or more); (4) avoid - one lizard runs rapidly away from the other, often running from one side of the observation chamber to the other (this typically occurs when one lizard is lunged at or chased by the other, but may occur when the other lizard shows no obvious aggression), and (5) tail twitch - movement of the tail back and forth, usually slowly and deliberately, but sometimes rapidly. We counted the number of times each lizard performed avoidance behavior and designated the lizard that fled the most as the subordinate; the other lizard was designated as the dominant. There was never any ambiguity in these designations owing to the dramatic disparity in the frequency of avoidance behavior.

In addition to behaviors, we also measured the following for each lizard: time (to the nearest second) spent on the "home" side of the observation chamber, time spent on the opposite side of the chamber, and time spent under the retreat. We also measured how much time the two lizards spent on the same side of the observation chamber and how much time they spent on opposite sides to ascertain if dominance relationships between the two lizards influenced use of space by either lizard. To account for intervals when one or both skinks were under the retreat, we defined two additional variables: (1) "to- gether" - the amount of time the two skinks were on the same side of the observation chamber plus the amount of time they were under the retreat together; (2) "apart" - the amount of time the two skinks were on opposite sides of the chamber plus the amount of time one lizard was under the retreat while the other was not. Finally, we compared the amount of time the two lizards occupied the retreat simultaneously to the amount of time the two lizards would be expected to occupy the retreat simultaneously if each lizard's occupancy of the retreat was unaffected by the presence of the other lizard in the retreat. The expected co-occupancy time was calculated by multiplying the proportion of time the dominant lizard occupied the retreat by the proportion of time the subordinate lizard occupied the retreat by 3600 seconds $(=60$ min) (Paulissen and Moran 2017).

We used paired t-tests to compare means of the number of times various behaviors were performed and to compare the mean amount of time the dominant and subordinate lizards spent on their home side, the opposite side, and in the retreat alone. We also used paired t-tests to compare means of the amounts of time lizards spent on the same side versus opposites sides of the observation, "together" versus "apart", and actual versus expected amount of time lizards occupied the retreat simultaneously. We ran a series of Pearson correlation coefficients to determine if there was any significant correlation between the difference in SVL between the two females and any of the behaviors we recorded. We used Kruskal-Wallis tests to compare the mean number of aggressive behaviors (lunge, chase, bite) exhibited by female $S$. lateralis in this study versus male $S$. lateralis reported in Myers and Paulissen (2017). We used a Binomial test to determine if the number of trials in which the dominant female was the larger one differed significantly from random chance. Finally, we used a Chi-squared test with Yate's correction for small sample sizes to compare the number of trials (out of 10) for each sex in which aggressive behaviors were exhibited. All statistics were computed with MYSTAT 12 for Windows (Mystat 2007). We report descriptive statistics as mean \pm standard error; a for all tests $=0.05$.

\section{RESULTS}

Female S. lateralis Behavior and Space Use - The mean number of encounters per trial was $17.2 \pm 2.92$ (minimum $=4$; maximum $=32$ ). Of these, an average of $1.7 \pm 0.65$ (approximately $10 \%$ ) resulted in no reaction by either lizard. In the remainder of the encounters, at least one lizard displayed one of the behaviors described in the Materials and Methods section. By far the most common behavior displayed was avoidance; overtly aggressive behaviors such as lunge and chase were uncommon and biting was never observed (Table 1 ). The subordinate female repeatedly fled from the dominant female, often to the opposite side of the observation chamber from where the dominant female was located. This occurred both when the dominant approached the subordinate and when the reverse occurred. Subordinate female $S$. lateralis also performed the tail twitch behavior significantly more often than did dominant females, though the magnitude of the difference was not as great as that of the avoidance behavior (Table 1). Though more commonly displayed by dominant females, there were no significant differences in the number of lunge and chase behaviors displayed by the dominant versus the subordinate females due to the overall low frequency of these behaviors (Table 1 ). 
Body measurements for the adult female $S$. lateralis used in this study was $47.4 \pm 1.46 \mathrm{~mm} \mathrm{SVL}$ and $1.8 \pm$ $0.146 \mathrm{~g}$ mass. The female with the larger SVL was dominant in 8 of the 10 trials. In the single trial in which the two females were the same SVL, the one with the greater mass was dominant. Thus in 9 of 10 trials, the larger of the two females was dominant; this is a statistically significant departure from random chance (Binomial test: $P=0.0107)$. There were no significant correlations between the difference in SVL between the two females and the frequency of any of the behaviors that we measured (all $P>0.05$ ).

Both the dominant and the subordinate female S. lateralis spent about the same amount of time on their home side of the observation chamber as they did on the opposite side (Figure 1). The dominant female spent more time on average under the retreat than the subordinate female, but the difference was not statistically significant (paired t-test: $\mathrm{t}=1.1, \mathrm{df}=9, P=0.288$; Figure 1 ).

When both skinks were outside the retreat, they spent more time on opposite sides of the observation chamber than on the same side, though the difference was not statistically significant (Figure 2a: FEMALE). When we factor in the amount of time either one or both females spent under the retreat, the two female $S$. lateralis spent significantly more time "apart" than "together" (Figure 2b: FEMALE). This was because most encounters between the two female $S$. lateralis ended with the subordinate avoiding the dominant, often by fleeing to the opposite side of the observation chamber. Furthermore, the two female $S$. lateralis rarely shared the retreat (mean \pm SE number of seconds both females under retreat $=$ $26.4 \pm 11.8)$. This number is significantly less than the expected time the two lizards should share the retreat if both lizards used the retreat at random (mean \pm SE expected time under the retreat together $=174.1 \pm 38.7$; paired t-test: $\mathrm{t}=4.02 ; \mathrm{df}=9, P=0.003$ ). Typically, if the subordinate female was under the retreat and the dominant entered, the subordinate left the retreat within a few seconds. If the dominant female was under the retreat when the subordinate tried to enter, the subordinate either turned away before entering fully, or entered, stayed a few seconds, then came back out again.

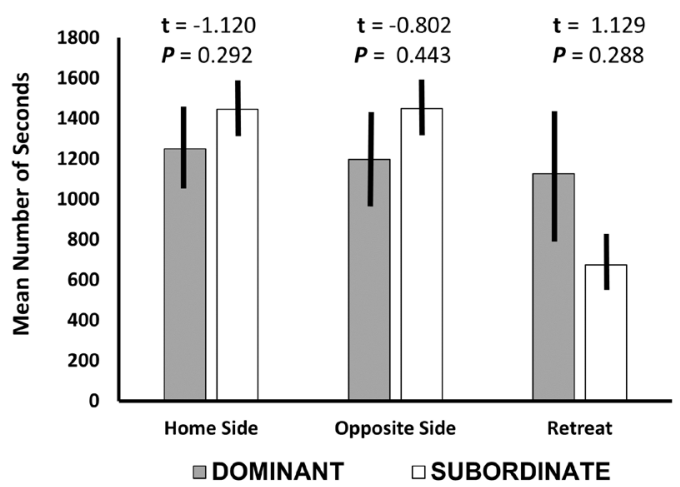

Fig. 1. Mean number of seconds dominant and subordinate female Scincella lateralis spent on their home side of the observation chamber, the opposite side of the observation chamber, and under the single retreat in the center of the observation chamber; vertical lines represents \pm 1 standard error. The results of paired t-tests for each category are shown; $d f=9$ for all tests. There were no significant differences between dominant and subordinate $S$. lateralis females for any category.
$2 a$.
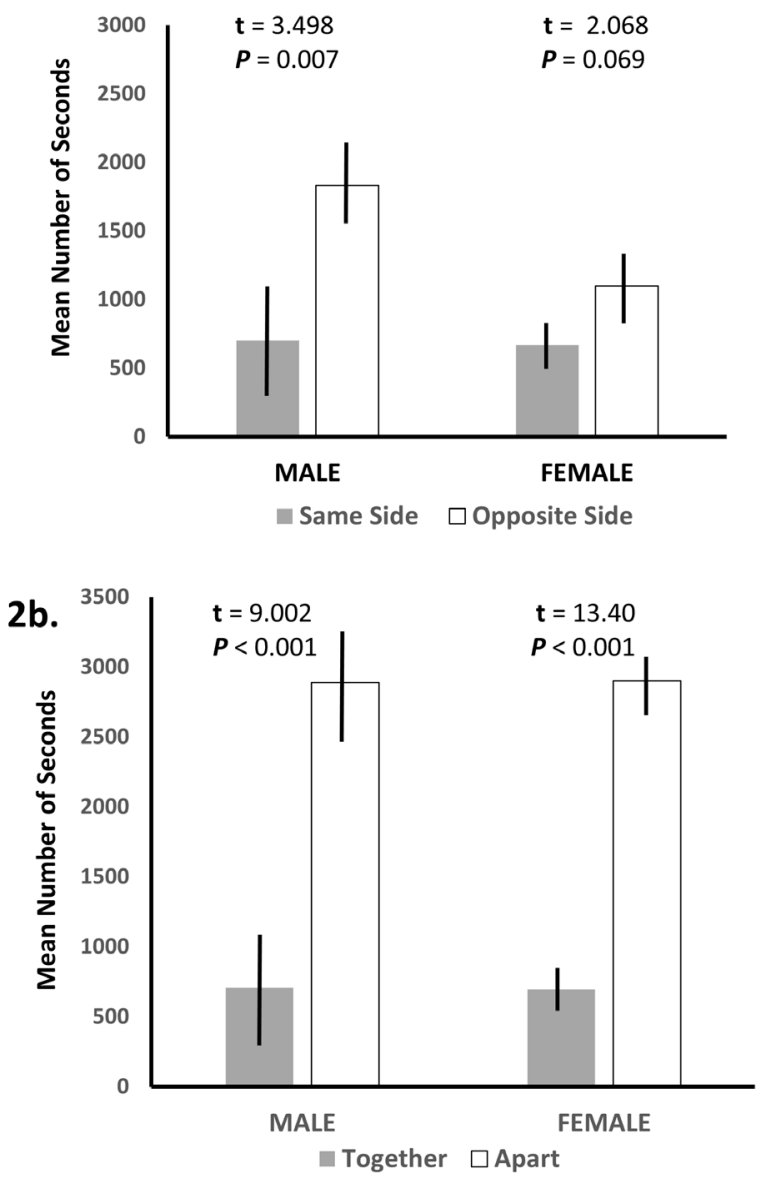

Fig. 2. Space use by male and female Scincella lateralis in 60-minute trials in the observation chamber. 2a. Mean number of seconds male and female $S$. lateralis spent on opposite sides of the observation chamber; $2 \mathrm{~b}$. Mean number of seconds male and female S. lateralis spent together and apart (See Methods and Materials). Vertical lines represents \pm 1 standard error. The results of paired t-tests comparing the mean time spent on the same side vs. the opposite side ( $2 a$ ) and comparing together vs. apart ( $2 \mathrm{~b})$ are shown for both males and females; $\mathrm{df}=9$ for all tests.

Comparison of Female to Male S. Iateralis Behavior and Space Use - The methods used in this study are the same as those of Myers and Paulissen (2017) on male $S$. lateralis. This makes it possible to make a direct comparison of the behavior and space use of female to male $S$. lateralis. The biggest difference was that the mean number of all three aggressive behaviors pooled (lunge, chase, and bite) displayed during $60 \mathrm{~min}$ trials by females was significantly lower than the mean number of aggressive behaviors exhibited by males (Table 2). This was because among females, lunging and chasing were rare and biting was never observed in any of the 10 trials. Indeed, aggressive behaviors were observed in only 4 of the 10 female trials. In contrast, all three aggressive behaviors were commonly observed in male trials, and 9 of 10 trials showed aggressive behaviors. This difference narrowly fails to reach statistical significance using a Chisquared test with Yate's correction for small sample size (Table 2). 
The relative frequency of tail twitches by dominant versus subordinate lizards differed between male and female $S$. lateralis. In males, there was no significant difference in tail twitching frequency between dominants and subordinates (Myers and Paulissen 2017). In females, however, subordinate lizards tail twitched significantly more frequently than did dominant lizards (Table 1). However, the mean number of tail twitches exhibited by dominant males toward their rivals was significantly greater than the mean number of tail twitches exhibited by dominant females toward their rivals (Table 2). No such difference exists in mean number of tail twitches performed by subordinate males versus subordinate females (Table 2).

Despite the lower number of aggressive behaviors in female trials, the space use by females was nearly the same as that of males. In both, the two lizards spent more time on opposite sides of the observation chamber than on the same side (though failing to reach statistical significance in females, Figure 2a). Similarly, in both male and female trials, the two lizards spent significantly more time apart than together (Figure 2b). In both the male and female trials, the dominant and subordinate lizards rarely occupied the retreat simultaneously (mean \pm SE $8.3+4.3 \mathrm{sec}$ for male trials; $26.4+11.8 \mathrm{sec}$ for female trials; $\mathrm{t}=1.439, \mathrm{df}=18, P=0.177$ ). Overall, space use by female $S$. lateralis reported in this study was very similar to that of space use by male $S$. lateralis reported by Myers and Paulissen (2017).

TABLE 2. Comparison of frequency of behaviors exhibited by adult male and adult female Scincella lateralis during 60-minute observation periods in the observation chamber. The first 5 variables are all mean \pm SE number of times male and female $S$. lateralis performed the behaviors with the $P$-value of Kruskal-Wallis tests comparing the male trials to female trials shown. "Number of Aggressive Interactions" is the sum of the number of lunges, chases, and bites. The last variable is the number of trials that aggressive behaviors were observed in the 10 male trials and the 10 female trials with the $P$-value of a Chi-squared test with Yate's correction shown. Data on males were taken from Myers and Paulissen (2017), data on females are taken from this study.

\begin{tabular}{cccc}
\hline & Males & Females & P-Value \\
\hline $\begin{array}{c}\text { Number of } \\
\text { Aggressive } \\
\text { Behaviors }\end{array}$ & $8.1 \pm 3.57$ & $1.1 \pm 0.55$ & 0.011 \\
$\begin{array}{c}\text { Number of } \\
\text { Avoidances by } \\
\text { Dominants } \\
\text { Number of }\end{array}$ & $0.2 \pm 0.13$ & $1.1 \pm 0.67$ & 0.148 \\
$\begin{array}{c}\text { Avoidances by } \\
\text { Subordinates } \\
\text { Number of Tail } \\
\text { Twitches by } \\
\text { Dominants }\end{array}$ & $1.4 \pm 0.48 \pm 6.83$ & $12.4 \pm 2.00$ & 0.121 \\
$\begin{array}{c}\text { Number of Tail } \\
\text { Twitches by } \\
\text { Subordinates } \\
\text { Number of Trials } \\
\text { (of 10) in which } \\
\text { aggressive } \\
\text { behavior was } \\
\text { observed }\end{array}$ & $0.9 \pm 0.32$ & $1.1 \pm 0.38$ & 0.718 \\
\hline
\end{tabular}

\section{DISCUSSION}

The behaviors exhibited by female $S$. lateralis in this study are typical of skinks in general. There were no interactions between lizards unless they were within one body length (about $45 \mathrm{~mm}$ ) of each other and there were no indications of any sort of visual communication, such as a display with the head, mouth, legs, or tail, between lizards that were more than a body length apart. The most commonly observed behavior was avoidance of one lizard by the other. This behavior, which includes flight of one lizard from the other, was recorded more often than all other behaviors combined (Table 1). Avoidance behavior is common in skinks (Paulissen and Moran 2017; Sanchez-Hernandez and Molina-Borja 2019) including S. lateralis (Akin 1998; Myers and Paulissen 2017). In over $90 \%$ of the encounters, it was the subordinate lizard that fled, presumably to avoid being near the dominant. Frequent avoidance behavior results in female $S$. lateralis spacing themselves apart from each other so they are often on opposite sides of the observation chamber, or are otherwise "apart", and almost never share a retreat (see Results). The tendency of skinks to space themselves so that they are they seldom close to each other has been noted both in field studies (Fitch and von Aachen 1977; Jennings and Thompson 1999) and in lab studies (Myers and Paulissen 2017; Paulissen and Moran 2017).

Our research showed that size is critical in determining dominance in female S. lateralis: in 9 of 10 trials, the larger of the two females was dominant. This result agrees with what has been found for both female (Akin 1998) and male (Myers and Paulissen 2017) S. lateralis and for skinks in general (Zwickel and Allison 1986; Cooper and Vitt 1987; Whittier and Martin 1992; Torr and Shine 1996; Paulissen and Moran 2017; Baines et al. 2020). Larger size in lizards is typically associated with superior capacity to threaten or to fight (Cooper and Vitt 1987; López and Martín 2001). In female S. lateralis, however, threat displays and fighting were not observed and aggressive behavior was extremely rare (Table 1 ). This raises the question of why size is so important in determining dominance. Presumably when two female $S$. lateralis come close to each other, they are able to assess relative size and can quickly determine which lizard is larger and therefore dominant without resorting to displays or aggression. Why the smaller, subordinate female should then flee to avoid the dominant when it is unlikely to be attacked is unknown.

The only behavior we observed from female S. lateralis that might be considered a form of direct communication is tail twitching. In this study, tail twitching was exhibited significantly more often by subordinate females than by dominant females, but only when the dominant moved near the subordinate, or when the subordinate moved close to the dominant. Taken alone, this observation suggests that tail twitching may serve as a form of communication by subordinate females toward dominant ones. However, we observed no obvious reaction by the dominant female to the tail twitching by the subordinate (or vice versa) and there was no correlation between size difference between the two females and tail twitching or any behavior. Furthermore, a close look at the data reveals that those few trials in which a dominant female did display tail twitching were also the few trials in which the dominant female also chased the subordinate female, perhaps suggesting that tail twitching by dominant females is related to aggressiveness. In our 
previous study of behavioral interactions between male $S$. lateralis, we observed that the dominant males tail twitched more frequently than did subordinate males, though the difference was not statistically significant (Myers and Paulissen 2017). This led us to hypothesize that tail twitching was not a social signal for male $S$. lateralis but more likely a sign of agitation. However, the comparison of males from that study to females in this study shows dominant males tail twitched significantly more frequently in male trials than dominant females did in female trials, though there was no corresponding difference in frequency of tail twitches between subordinate males and females (Table 2). The fact that male $S$. lateralis display aggressive behaviors more frequently than females lends support to the hypothesis that tail twitching is related to aggressiveness. The literature on skink behavior has documented tail twitching or tail wriggling behaviors in many species and several different explanations for it have been proposed. For example, Langkilde et al. (2003; 2004) described three levels of "tail wave" exhibited by Carlia jarnoldae, the Lined Rainbow-skink, noting that tail waving is rarely performed by solitary skinks, and therefore may be a signal by resident males directed towards intruders. By contrast, at least two studies have suggested that tail twitching may be a signal given by subordinate skinks toward dominant ones. Perrill (1980) described a slow "tail wag" displayed by juvenile Plestiodon (formerly Eumeces) inexpectatus, the Southeastern Five-Lined skink, towards adults as a sign of submission. Sanchez-Hernandez et al. (2012) described a "tail undulation" usually displayed by subordinate individuals of Chalcides viridanus in response to another skink's display. Torr and Shine (1994) described "tail lashing" and "tail twitching" by Lampropholis guichenoti, the Common Garden skink, and noted these behaviors were displayed by both dominants and subordinates. In a later study, these authors suggested that while tail twitching may be a social signal, it may also serve an antipredator function or be a sign of agitation (Torr and Shine 1996). The foregoing demonstrates that the function of tail twitching in S. lateralis and other skinks cannot be presently identified. The determination of whether tail twitching by skinks is a social signal, a sign of aggressiveness, a sign of agitation, or some combination of these (or other) functions must await further detailed study of both sexes of a variety of species.

Female $S$. lateralis never bit each other and exhibited aggressive behaviors (lunge and chase) far less frequently than did the male $S$. lateralis studied by Myers and Paulissen (2017). This suggests female S. lateralis are less aggressive in their social interactions than are males. Similarly, Akin (1998) found that overt aggression between female $S$. lateralis was rare (though he did record a single instance of a female biting another) whereas male $S$. lateralis frequently interacted aggressively with each other. The few studies of skinks that have addressed behavioral interactions of both males and females have shown males tend to exhibit more aggression in intrasexual encounters than do females (Zwickel and Allison 1986; Sanchez-Hernandez and Molina-Borja 2019). This sex difference in aggression levels in skinks matches what has been found in the better studied species of the Iguanian clade. However, all these studies, including this one, were conducted under artificial conditions in which lizards were brought into close proximity to increase the likelihood of them encountering each other so they may interact. Due to their secretive nature, skinks are noto- riously difficult to study under natural conditions, so it is not known if the sex differences in levels of aggression and spacing patterns identified in this and related studies occur in natural conditions. The conclusions of these studies should be considered as starting points to guide the design of studies of behavioral interactions of skinks in their natural environment. Only detailed studies of a large cross-section of species from this enormous lizard family will enable herpetologists to fully understand the complexities of squamate behavior.

\section{ACKNOWLEDGMENTS}

Part of this research was completed by L. Myers in partial fulfillment of the requirements for graduating with Honors from Northeastern State University (NSU); we thank Dr. Karen Carey and the NSU Honors Program for their assistance. Support for this project was provided by an NSU Faculty Research Committee grant awarded to M. Paulissen. We thank Brian Becker for aiding in capturing and caring for the lizards. The research protocols were approved by the NSU Animal Welfare Committee (IACUC \#2010-02; subsequently renewed for the duration of the study). Lizards were collected under the authority of Scientific Collecting Permits (\#5265, \#5530, and \#5903) granted to M. Paulissen by the Oklahoma Department of Wildlife Conservation.

\section{LITERATURE CITED}

Akin, J. A. 1998. Intra- and inter-sexual aggression in the ground skink (Scincella lateralis). Canadian Journal of Zoology 76:87-93.

Baines, H., B. Gini, Y-M. Chang, and C. J. Michaels. 2020. Dominance and aggression in captive gidgee skinks (Egernia stokesii). Herpetological Journal 30:83-92.

Baird, T. A. 2013. Male collared lizards, Crotaphytus collaris, (Sauria:Crotaphytidae), signal female by broadcasting visual displays. Biological Journal of the Linnaean Society 108:636-646.

Baird, T. A., C. L. Sloan, and D. K. Timamus. 2001. Intra- and Inter-seasonal variation in the socio-spatial behavior of adult male collared lizards, Crotaphytus collaris (Reptilia, Crotaphytidae). Ethology 107:15-32.

Brooks, G. R. 1967. Population ecology of the ground skink, Lygosoma laterale (Say). Ecological Monographs 37:71-87.

Carpenter, C. C. 1978. Comparative display behavior in the genus Sceloporus (Iguanidae). Contributions in $\mathrm{Bi}$ ology and Geology to the Milwaukee Public Museum. 18: $1-71$.

Carpenter, C. C., and G. W. Ferguson. 1977. Variation and evolution of stereotyped behavior in reptiles. Pp. 335-554, In: Gans, C., and T. W. Tinkle. Biology of the Reptilia Volume 7: Ecology and Behaviour A. Academic Press, New York, NY.

Cooper, Jr., W. E., and L. J. Vitt. 1987. Deferred agonistic behavior in a long-lived scincid lizard Eumeces laticeps. Oecologia 72:321-326.

Cooper, Jr., W. E., and L. J. Vitt. 1997. Maximizing male reproductive success in the broad-headed skink (Eumeces laticeps): preliminary evidence for mate-guarding, size-assortative pairing, and opportunistic extra-pair mating. Amphibia-Reptilia 18:59-73.

Fitch, H. S., and P. L. von Achen. 1977. Spatial relationships and seasonality in the skinks Eumeces fasciatus and Scincella laterale in northeastern Kansas. Herpetologica 33:303-313. 
Fox, S. F., E. Rose, and R. Myers. 1981. Dominance and the acquisition of superior home ranges in the lizard Uta stansburiana. Ecology 62:888-893.

Haenel, G.J., L. C. Smith, and H. B. John-Alder. 2003. Home-range analysis in Sceloporus undulatus (Eastern Fence Lizard). I. Spacing patterns and the context of territorial behavior. Copeia 1983: 99-112.

Jennings, W. B., and G. G. Thompson. 1999. Territorial behavior in the Australian scincid lizard Ctenotus fallens. Herpetologica 55:352-361.

Langkilde, T., L. Schwarzkopf, and R. Alford. 2003. An ethogram for adult male rainbow skinks, Carlia jarnoldae. Herpetological Journal 13:141-148.

Langkilde, T., L. Schwarzkopf, and R. Alford. 2004. The function of tail displays in male rainbow skinks, Carlia jarnoldae. Journal of Herpetology 37:328-335.

Lewis, T. H. 1951. The biology of Leiolopisma laterale (Say). American Midland Naturalist 45:232-240.

López, P. and J. Martín. 2001. Fighting rules and rival recognition reduce costs of aggression in male lizards, Podarcis hispanica. Behavioral Ecology and Sociobiology 49: 111-116.

Martins, E. P. 1994. Phylogenetic perspectives on the evolution of lizard territoriality. Pp. 115-144, In: Vitt, L. J., and E. R. Pianka. Lizard Ecology: Historical and Experimental Perspectives. Princeton University Press, Princeton, NJ.

Myers, L. M. and M. A. Paulissen. 2017. Aggressive behaviors and their effect on resource use by male little brown skinks, Scincella lateralis. Journal of North American Herpetology. 2017(1): 5-10.

MYSTAT 2007. MYSTAT 12 for Windows. Systat Software, Inc. USA.

Paulissen, M. A. and D. A. Moran. 2017. Intraspecific aggression in neonate common Five-Lined Skinks (Plestiodon fasciatus). Journal of Herpetology 51:477-481.

Perrill, S. A. 1980. Social communication in Eumeces inexpectatus. Journal of Herpetology 14:129-135.

Sanchez-Hernandez, P, M. P. Ramirez-Pinilla, and M. Molina-Borja. 2012. Agonistic and courtship behaviour patterns in the skink Chalcides viridanus (Fam. Scincidae) from Tenerife. Acta Ethologica 15:65-71.
Sanchez-Hernandez, P. and M. Molina-Borja. 2019. Development and outcome of intrasexual contests in males and females of Chalcides viridanus (Fam. Scincidae) along breeding period. Behaviour 156: 13491369 .

Sheldahl, L. A. and E. P. Martins. 2000. The territorial behavior of the western fence lizard, Sceloporus occidentalis. Herpetologica 56:469-479.

Sinn, D. L., G.M. While, and E. Wapstra. 2008. Maternal care in a social lizard: links between female aggression and offspring fitness. Animal Behaviour 76:12491257.

Sites, J. W., T. W. Reeder, and J. J. Wiens. 2011. Phylogenetic insights on evolutionary novelties in lizards and snakes: sex, birth, bodies, niches, and venom. Annual Review of Ecology, Evolution, and Systematics 42:227-244.

Stamps, J. A. 1977. Social behavior and spacing patterns in lizards. Pp. 265-334, In: Gans, C., and T. W. Tinkle. Biology of the Reptilia Volume 7: Ecology and Behaviour A. Academic Press, New York, NY.

Torr, G. A., and R. Shine. 1994. An ethogram for the small scincid lizard Lampropholis guichenoti. Amphibia-Reptilia 15:21-34.

Torr, G. A., and R. Shine. 1996. Patterns of dominance in the small scincid lizard Lampropholis guichenoti. Journal of Herpetology 30:230-237.

Vitt, L. J., and J. P. Caldwell. 2014. Herpetology: An Introductory Biology of Amphibians and Reptiles, Fourth Edition. Academic Press, New York, NY.

Whittier, J. M., and J. Martin. 1992. Aspects of social behaviour and dominance in male rainbow skinks, Carlia rostralis. Australian Journal of Zoology 40:73-79.

York, J. R. and T. A. Baird. 2017. Sexual selection on male collared lizard (Crotaphytus collaris) display behaviour enhances offspring survivorship. Biological Journal of the Linnean Society 20: 1-8.

Zwickel, F. W., and A. Allison. 1986. Inter- and intra-sexual interactions in a New Guinea skink, Emoia physicae. Canadian Journal of Zoology 64:752-755. 